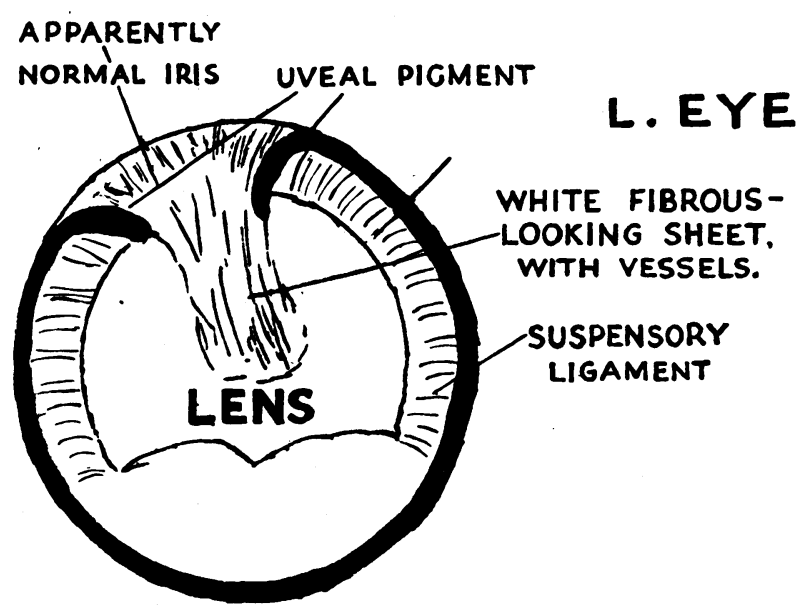

The tension after operation was much better in the right eye, varying from 15 to $23 \mathrm{~mm}$. $\mathrm{Hg}$. The left was not improved.

Seen in January, 1930, the child was still rather photophobic, but seemed to be using its eyes more, and was said by the parents to be seeing its food, toys, etc., quite well.

The case is interesting in view of the close connection of buphthalmia with congenital abnormalities; also the intense photophobia is not a usual symptom, but probably due to the excessive amount of light entering the left eye.

\title{
ANNOTATIONS
}

\section{Development of Ophthalmology in Europe}

Some interesting observations on this subject were made by Professor Fuchs in his dedicatory address at the opening of the Wilmer Ophthalmological Institute. Ophthalmology may justifiably be regarded as the senior speciality in medicine and surgery as it split away from its parent stem no less than three thousand four hundred years ago, in the time of dynastic Egypt. The use of copper sulphate in the treatment of what may truly be called Egyptian ophthalmia was well known in those days, when there were also a number of other specific cures for eye diseases, as described in the Papyrus Ebers. After the fall of the Roman Empire there was complete stagnation in ophthalmology which persisted until the middle ages when spectacles were invented, not by oculists but by physicists who based their work on Kepler's doctrines. Arabic oculists, though men of great fame in their time, did relatively nothing to advance matters, since they limited themselves to translating the books of ancient authors such as 
Hippocrates, Galen and Celsus, giving only poor additions of their own.

It took a long time for ophthalmology to make much headway as a speciality in Europe. Couchers and quacks abounded but a professorial chair was not founded until comparatively recently, the first one being in Vienna. It is curious that even the famous von Graefe did not have one of his own until 1866, four years before his death. Paris did not follow the example of Vienna until 1879, whereas Harvard established a chair in 1871 with Henry Willard Williams as incumbent.

The enormous modern development of ophthalmology has been the work of the last hundred years and due largely to the invention of new methods of examination. The names of Mackenzie, who originated focal illumination, Helmholtz, Cuignet and Donders speak for themselves in a roll of inventors of diagnostic instruments and procedures. von Graefe's name is so intimately associated with iridectomy for acute glaucoma, that we are a little apt to overlook the importance of his work in connection with perimetry. Professor Fuchs related an interesting story of how a beggar who was led about the streets and earned his living by his blindness, was discovered in the act of reading and regarded as a cheat. The police brought him to von Graefe who, by taking the field, discovered that only central vision was present, the patient being a sufferer from retinitis pigmentosa.

On the operative side the important landmarks are 1746 when Daviel substituted extraction of cataract for couching, 1857 when von Graefe discovered iridectomy for glaucoma, and 1884 when Carl Koller first used cocaine as a local anaesthetic for eye operations.

\section{A Memento of a Famous Ophthalmic Charlatan}

Through the kindness of $\mathrm{Mr}$. Treacher Collins we had the opportunity, not long ago, of examining a snuff-box which would appear to have been at one time the property of Sir William Read, Queen Anne's oculist and a noted ophthalmic impostor. The box is of silver with a mother-of-pearl lid and is in the shape of an oyster . shell, measuring $3 \frac{1}{4}$ by 3 by $\frac{1}{2}$ an inch. The lid is engraved, the upper third being adorned by a diaper pattern; next comes a narrow space divided into two parts, the left hand space containing the following sentence: "I fight for Innosentes, Sr. William Read "; that on the other side having: "This as on[e] of my defenders ye lord hath sent me." The lower part of the lid shows at the right hand part, below, an effigy of a baby, wrapped in swaddling clothes and lying amid rushes, rather like Moses in the bulrushes and above this, the word "England." On the left hand 